\title{
Article \\ Correlation of Electrical Properties and Acoustic Loss in Single Crystalline Lithium Niobate-Tantalate Solid Solutions at Elevated Temperatures
}

\author{
Yuriy Suhak ${ }^{1, *}$, Dmitry Roshchupkin ${ }^{2} \mathbb{D}$, Boris Redkin ${ }^{3}$, Ahsanul Kabir ${ }^{1}$, Bujar Jerliu ${ }^{1} \mathbb{D}$, Steffen Ganschow ${ }^{4} \mathbb{D}$ \\ and Holger Fritze 1 \\ 1 Institute for Energy Research and Physical Technologies, Clausthal University of Technology, Am Stollen 19B \\ 38640 Goslar, Germany; ahsanul.kabir@tu-clausthal.de (A.K.); bujar.jerliu@tu-clausthal.de (B.J.) \\ 2 Institute of Microelectronics Technology and High Purity Materials, Russian Academy of Sciences, \\ Academician Ossipyan Str. 6, 142432 Chernogolovka, Russia; rochtch@iptm.ru \\ 3 Institute of Solid State Physics, Russian Academy of Sciences, Academician Ossipyan Str. 2, \\ 142432 Chernogolovka, Russia; redkin@issp.ac.ru \\ 4 Leibniz-Institut für Kristallzüchtung, Max-Born-Str. 2, 12489 Berlin, Germany; \\ steffen.ganschow@ikz-berlin.de \\ * Correspondence: sensorik@tu-clausthal.de
}

check for

updates

Citation: Suhak, Y.; Roshchupkin, D.; Redkin, B.; Kabir, A.; Jerliu, B.;

Ganschow, S.; Fritze, H. Correlation of Electrical Properties and Acoustic Loss in Single Crystalline Lithium Niobate-Tantalate Solid Solutions at Elevated Temperatures. Crystals 2021, 11, 398. https://doi.org/10.3390/ cryst11040398

Academic Editors: Gábor Corradi and László Kovács

Received: 3 March 2021

Accepted: 7 April 2021

Published: 9 April 2021

Publisher's Note: MDPI stays neutra with regard to jurisdictional claims in published maps and institutional affiliations.

Copyright: (c) 2021 by the authors. Licensee MDPI, Basel, Switzerland. This article is an open access article distributed under the terms and conditions of the Creative Commons Attribution (CC BY) license (https:/ / creativecommons.org/licenses/by/ $4.0 /)$.
Abstract: Electrical conductivity and acoustic loss $Q^{-1}$ of single crystalline $\mathrm{Li}(\mathrm{Nb}, \mathrm{Ta}) \mathrm{O}_{3}$ solid solutions (LNT) are studied as a function of temperature by means of impedance spectroscopy and resonant piezoelectric spectroscopy, respectively. For this purpose, bulk acoustic wave resonators with two different $\mathrm{Nb}$ / Ta ratios are investigated. The obtained results are compared to those previously reported for congruent $\mathrm{LiNbO}_{3}$. The temperature dependent electrical conductivity of LNT and $\mathrm{LiNbO}_{3}$ show similar behavior in air at high temperatures from 400 to $700{ }^{\circ} \mathrm{C}$. Therefore, it is concluded that the dominant transport mechanism in LNT is the same as in LN, which is the Li transport via Li vacancies. Further, it is shown that losses in LNT strongly increase above about $500{ }^{\circ} \mathrm{C}$, which is interpreted to originate from conductivity-related relaxation mechanism. Finally, it is shown that LNT bulk acoustic resonators exhibit significantly lower loss, comparing to that of $\mathrm{LiNbO}_{3}$.

Keywords: lithium niobate-tantalate; piezoelectric; acoustic; high-temperature; sensor; $Q$-factor; BAW resonator

\section{Introduction}

Piezoelectric resonant sensors are attracting considerable interest since they offer numerous advantages for multiparameter in-situ monitoring and control of industrial processes. In particular, there is an increasing need in sensitive, robust and cost-effective sensors for gas composition, temperature and pressure for the application at high-temperatures or generally in harsh environments [1-3]. The working principles of such sensors are based on frequency shifts that arise from external factors such as temperature or mass load. Therefore, it is important to maximize their resonance quality factor ( $Q$-factor), which allows, e.g., improved accuracy and better stability in frequency-control applications [3].

Further, piezoelectric actuators, which can generate movements in the micrometer range upon application of voltage, are demanded in automotive, aerospace and related industrial applications. For example, automotive applications such as fuel injection nozzles require operation at elevated temperatures $[3,4]$.

However, the application temperature of common piezoelectric materials is limited. For example, usage of lead zirconium titanate (PZT) ceramics actuators at hightemperatures is limited by thermal instability at around $200-250{ }^{\circ} \mathrm{C}$ for most PZT compositions [3-5]. On the other hand, crystals from the langasite $\left(\mathrm{La}_{3} \mathrm{Ga}_{5} \mathrm{SiO}_{14}\right)$ family show 
relatively high stability at high temperatures, however their piezoelectric coefficients are too small to use them as actuating devices [2,6,7].

Lithium niobate $\left(\mathrm{LiNbO}_{3}, \mathrm{LN}\right)$ and lithium tantalate $\left(\mathrm{LiTaO}_{3}, \mathrm{LT}\right)$ attracted substantial scientific and industrial interest in the last decades because of its excellent electrooptical, piezoelectric and acoustic properties [8-10]. Both compounds are isostructural (point symmetry group $3 m$, space group $R 3 c$ ) with only slight differences in the lattice parameters $[8,10,11]$. Both LN and LT have a congruently melting composition with an approximate lithium content of about $48.4 \mathrm{~mol} \% \mathrm{Li}_{2} \mathrm{O}$. These materials possess high piezoelectric coefficients (10 times higher comparing to langasite), which allows generating appreciable and useful strain under an applied electric field, enabling their usage not only as surface or bulk acoustic wave sensors, but also as actuators [12,13]. $\mathrm{LiTaO}_{3}$ shows good thermal stability of sensing-relevant parameters (e.g., resonance frequency or quality factor), however, its application is limited by a relatively low Curie temperature of about $630{ }^{\circ} \mathrm{C}$ [14]. The Curie temperature of $\mathrm{LN}$ is about $1200{ }^{\circ} \mathrm{C}$, but its thermal stability at elevated temperatures is relatively poor. $\mathrm{Li}_{2} \mathrm{O}$ out-diffusion and evaporation and, finally, chemical decomposition [15] impact the performance of LN bulk acoustic resonators, such as quality-factor or resonance frequency $[15,16]$. Moreover, an increasing material dependent loss for different bulk vibration modes is observed above $700{ }^{\circ} \mathrm{C}$ [16]. In this respect, single crystalline lithium niobate-tantalate solid solutions $\left(\mathrm{Li}(\mathrm{Nb}, \mathrm{Ta}) \mathrm{O}_{3}, \mathrm{LNT}\right)$ are expected to combine the best properties, i.e., good thermal stability and high Curie temperature, of both end components of the system.

Several defect models have been proposed in the literature to describe Li-deficiency in congruent $\mathrm{LiNbO}_{3}$, which is commonly formed during the crystal growth. These models consider formation of $\mathrm{Li}-, \mathrm{Nb}$ - and O-vacancies [17-19]:

$$
\begin{gathered}
\mathrm{LiNbO}_{3} \rightarrow 3 \mathrm{Li}_{2} \mathrm{O}+4 \mathrm{~V}_{\mathrm{Li}}^{/}+\mathrm{Nb}_{\mathrm{Li}}^{4 \bullet} \\
\mathrm{LiNbO}_{3} \rightarrow 3 \mathrm{Li}_{2} \mathrm{O}+4 \mathrm{~V}_{\mathrm{Nb}}^{5 /}+5 \mathrm{Nb}_{\mathrm{Li}}^{4 \bullet} \\
\mathrm{LiNbO}_{3} \rightarrow \mathrm{Li}_{2} \mathrm{O}+2 \mathrm{~V}_{\mathrm{Li}}^{/}+\mathrm{V}_{\mathrm{O}}^{2 \bullet}
\end{gathered}
$$

However, the structural studies and the calculations performed in $[17,18]$ show a low probability for the formation of oxygen vacancies and higher charged $\mathrm{V}_{\mathrm{Nb}}{ }^{{ }^{\prime}}$ vacancies during crystal growth. Thus, mechanism (1) is considered to be energetically the most favorable. Here, compensation of $\mathrm{Nb}$ antisites occurs by Li-vacancies. In an analogy to the defect model for nonstoichiometric $\mathrm{LiNbO}_{3}$, the congruent $\mathrm{LiTaO}_{3}$ single crystals also contain a large amount of the tantalum antisites and cation vacancies [20-22]. The defect models for LNT are still to be established. However basing on LN and LT studies it is plausible to assume, that the Li-vacancy model could also be considered for congruent LNT crystals.

The high-temperature properties of LN and LT crystals are in general relatively well studied. In particular, the temperature-dependent electrical properties of LT were investigated in [23-26] and of LN in [16,27-32]. For both end components of the LNT system it is established that at elevated temperatures the conductivity is predominantly ionic and attributed to the motion of lithium ions via Li-vacancies [23,24,26-32]. Further, the elastic, dielectric and piezoelectric constants were determined for both end components of the $\mathrm{Li}(\mathrm{Nb}, \mathrm{Ta}) \mathrm{O}_{3}$ system as a function of temperature in [33-35]. In contrast, the electrical, structural and optical properties of LNT are scarcely studied so far [36-39]. Beyond these publications, to the best of our knowledge, no systematic studies on LNT were published. The piezoelectric properties of LN resonators were studied up to $500^{\circ} \mathrm{C}$ in [40] and up to $900^{\circ} \mathrm{C}$ in $[16,41]$. Finally, the temperature stability of LN-based piezoelectric transducers was examined in $[42,43]$.

The synthesis of single crystalline LNT solid solutions is challenging, largely because of great difference in melting temperatures $T_{\mathrm{m}}$ of both end components of the system $\left(T_{\mathrm{m}}\left(\mathrm{LiNbO}_{3}\right)=1240{ }^{\circ} \mathrm{C} ; T_{\mathrm{m}}\left(\mathrm{LiTaO}_{3}\right)=1650{ }^{\circ} \mathrm{C}\right)[44,45]$. The growth of high-quality LNT sin- 
gle crystals appears to have been achieved only recently in the United Kingdom [39,46,47], China [36] and by the groups, involved in this study. Therefore, the high-temperature properties of LNT compounds remain practically unstudied. In particular, the material constants of LNT-solid solutions are not available. To the best of our knowledge, only the electrical conductivity is investigated up to $850^{\circ} \mathrm{C}$. The results are published in $[48,49]$.

Based on the previous studies of acoustic loss in $\mathrm{LiNbO}_{3}[16,41]$ and in other piezoelectric materials [50-52], the following dissipation mechanisms can potentially contribute to the losses:

(1) Intrinsic phonon-phonon interactions,

(2) Anelastic point defect relaxations,

(3) Piezoelectric/carrier relaxation (conductivity-related losses),

(4) Non-material contribution (cables, mounting, etc.).

Phonon-phonon scattering can be the dominant loss mechanism at low temperatures (near and below room temperature) in the case of high-quality piezoelectric crystals $[53,54]$. This contribution exhibits, however, only weak temperature dependence above room temperature $[50,53]$. Therefore its contribution is minor at elevated temperatures. Consequently, it is neglected in the current study.

Anelastic relaxations can arise from point defects, which produce local anisotropic distortions in the crystal lattice [55]. The application of acoustic stress leads to time-delayed thermally activated reorientation of these defects. This process depends on frequency and temperature and can be described by a Debye function:

$$
Q^{-1}(\omega, T) \approx \frac{\Delta}{T} \frac{\omega \tau}{1+\omega^{2} \tau^{2}}
$$

where $\Delta$ is a temperature-independent constant proportional to the concentration of the defect species, $T$ is the absolute temperature, $\omega$ is the angular acoustic frequency (equal to $2 \pi \mathrm{f}$ ), and $\tau$ is the reorientation relaxation time of the defect. As will be shown in the subsequent sections, no evidence of dominating anelastic point defect relaxation was observed on $Q^{-1}(T)$ dependencies of the samples studied here so far.

Of particular relevance for $\mathrm{Li}(\mathrm{Nb}, \mathrm{Ta}) \mathrm{O}_{3}$ resonators is the dissipation that arises from piezoelectric/carrier relaxation. These conductivity-related losses are caused by the motion of charge carriers in an oscillating piezoelectric field. According to the theory of Hutson and White [56], this contribution has a Debye form, is frequency and temperature dependent and can be approximated by the following equation:

$$
Q_{c}^{-1}(\omega, T) \approx K^{2} \frac{\omega \tau_{c}}{1+\omega^{2} \tau_{c}^{2}}
$$

where $\omega$ is the angular frequency (equal to $2 \pi f$ ); $T$ and $K^{2}$ are the absolute temperature and the electromechanical coupling coefficient, respectively and $\tau_{c}$ is the relaxation time, with

$$
\tau_{c}=\frac{\varepsilon_{i j}}{\sigma}
$$

Here, $\sigma$ and $\varepsilon_{i j}$ denote the electrical conductivity and the dielectric permittivity, respectively. For the thickness-shear mode of Y-cut crystals from point group $3 m$, the electromechanical coupling coefficient is equal to $e_{15}^{2} /\left(C_{44} \varepsilon_{11}\right)$ in the reduced-index notation, where $e_{15}, C_{44}$ and $\varepsilon_{11}$ are the piezoelectric coefficient, the elastic stiffness and the dielectric permittivity, respectively [57]. For the thickness mode of $\mathrm{Z}$-cut $\mathrm{Li}(\mathrm{Nb}, \mathrm{Ta}) \mathrm{O}_{3}$ crystals the electromechanical coupling factor is defined as $e_{33}^{2} /\left(C_{33} \varepsilon_{33}\right)$ [57]

In the current paper the high-temperature electrical and electromechanical properties of single crystalline LNT with different $\mathrm{Nb}$ / Ta ratios, grown by the Czochralski technique [58] are studied and compared to the data, reported previously for LN [16,41]. The work presented here is the first step towards systematic studies of high-temperature electrical and acoustic properties of LNT crystals. It seeks to provide a better understanding 
of physical mechanisms that govern loss in $\mathrm{Li}(\mathrm{Nb}, \mathrm{Ta}) \mathrm{O}_{3}$ by combining determination of electrical conductivity and loss-related $Q^{-1}$ with the aim to obtain high-temperature stable material with large piezoelectric coefficients for possible actuating applications.

\section{Materials and Methods}

\subsection{Crystals}

$\mathrm{LiNb}_{0.88} \mathrm{Ta}_{0.12} \mathrm{O}_{3}$ and $\mathrm{LiNb}_{0.5} \mathrm{Ta}_{0.5} \mathrm{O}_{3}$ crystals, grown by the Czochralski technique were used in this study. $\mathrm{LiNb}_{0.88} \mathrm{Ta}_{0.12} \mathrm{O}_{3}$ was grown at the Institute of Microelectronics Technology and High Purity Materials, Russian Academy of Sciences, Chernogolovka, Russia (IMT). This crystal was grown along the polar axis $\mathrm{Z}$ in a Pt crucible (diameter of $60 \mathrm{~mm}$ and height of $60 \mathrm{~mm}$ ). Congruent $\mathrm{LiNbO}_{3}$ and $\mathrm{LiTaO}_{3}$ crystals were used as initial charges. The pulling rate of crystals from the melt was about $0.5 \mathrm{~mm}$ per hour. The obtained crystal boules have a diameter and a length of about $20 \mathrm{~mm}$ each as shown in Figure 1. The composition of the grown crystals was determined using mass spectrometry with inductively coupled plasma (XSeries II Thermo Scientific spectrometer, Waltham, MA, USA). The full report about the growth process and structural parameters of the obtained crystal is given in [58]. Additionally, the composition of $\mathrm{LiNb}_{0.88} \mathrm{Ta}_{0.12} \mathrm{O}_{3}$ was studied by energy-dispersive X-ray (EDX) spectroscopy (CamScan 44, Waterbeach, UK). These investigations were performed on two specimens, used for electrical and electromechanical measurements, which are described in Section 2.2. The $\mathrm{Nb} /$ Ta ratio was determined along the diameter of the specimens as a line scan with $0.8 \mathrm{~mm}$ step. In total 10 measurements per specimen were performed and the uncertainty of the measurements did not exceed $5 \%$. The results are summarized in Table 1. Most important, an insignificant inhomogeneity and small differences in $\mathrm{Nb} / \mathrm{Ta}$ distribution between two specimens are observed.

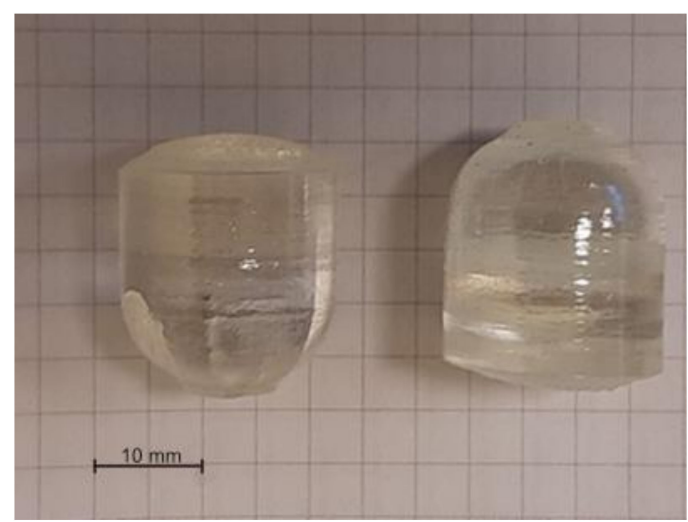

Figure 1. $\mathrm{LiNb}_{0.88} \mathrm{Ta}_{0.12} \mathrm{O}_{3}$ boules, grown by the Czochralski technique.

Table 1. $\mathrm{Nb} /$ Ta ratio in $\mathrm{LiNb}_{0.88} \mathrm{Ta}_{0.12} \mathrm{O}_{3}$ samples determined by an energy-dispersive X-ray (EDX).

\begin{tabular}{ccccccc}
\hline \multirow{2}{*}{ Measurement } & \multicolumn{3}{c}{ LNT88-01 } & \multicolumn{3}{c}{ LNT88-02 } \\
\cline { 2 - 7 } & Nb at.\% & Ta at. $\%$ & Nb/(Nb + Ta) & Nb at. \% & Ta at.\% & Nb/(Nb + Ta) \\
\hline 1 & 19.73 & 2.12 & 0.90 & 21.26 & 2.49 & 0.90 \\
2 & 19.75 & 2.61 & 0.88 & 21.45 & 2.44 & 0.90 \\
3 & 20.53 & 2.52 & 0.89 & 21.51 & 2.54 & 0.90 \\
4 & 20.72 & 2.42 & 0.90 & 21.30 & 2.49 & 0.90 \\
5 & 20.91 & 2.87 & 0.88 & 21.85 & 2.11 & 0.91 \\
6 & 21.00 & 2.73 & 0.88 & 21.59 & 2.06 & 0.91 \\
7 & 21.56 & 2.89 & 0.88 & 21.89 & 2.11 & 0.91 \\
8 & 21.38 & 2.32 & 0.90 & 22.36 & 2.07 & 0.91 \\
10 & 21.40 & 2.8 & 0.88 & 21.88 & 2.00 & 0.92 \\
\hline
\end{tabular}


A single crystal of nominal composition $\mathrm{LiNb}_{0.5} \mathrm{Ta}_{0.5} \mathrm{O}_{3}$ was grown at the LeibnizInstitut für Kristallzüchtung, Berlin, Germany (IKZ). Initial melt was a mixture of the congruently melting compositions of $\mathrm{LiNbO}_{3}$ and $\mathrm{LiTaO}_{3}$. Considering the strong segregation upon crystallization [46], the melt contained a $\mathrm{LiTaO}_{3}$ mole fraction of only 0.18 . The starting materials, previously dried and thoroughly mixed $\mathrm{Li}_{2} \mathrm{CO}_{3}$ (99.999\%, Alfa Aesar, Karlsruhe, Germany), $\mathrm{Nb}_{2} \mathrm{O}_{5}$ (99.995\%, H.C. Starck, Goslar, Germany) and $\mathrm{Ta}_{2} \mathrm{O}_{5}(99.99 \%$, Fox Chemicals, Pfinztal, Germany), were pressed isostatically and sintered at $1100{ }^{\circ} \mathrm{C}$. The obtained blank was melted in an inductively heated $40 \mathrm{~mL}$ iridium crucible covered by an active afterheater [59] and thermally isolated by a set of alumina ceramics. Growth atmosphere was high purity Ar with an admixture of approximately $1.3 \mathrm{vol} \% \mathrm{O}_{2}$. The crystal was grown at a rate of $0.5 \mathrm{~mm} / \mathrm{h}$ on a [00.1]-oriented $\mathrm{LiTaO}_{3}$ seed, provided by CrysTec $\mathrm{GmbH}$, Berlin. To minimize the impact of segregation, only $6 \%$ of the melt was crystallized. After growth the crystal was withdrawn from the melt and cooled down to room temperature within $15 \mathrm{~h}$. The obtained crystal was largely transparent of slight yellowish coloration, with a cylindrical part slightly more than $10 \mathrm{~mm}$ in both diameter and length. The crystal was not intentionally poled during or after the growth process, i.e., the domain structure after the growth was not defined. However, the existence of piezoelectrically exited resonances confirms that there are obviously sufficiently large areas with identical orientation of the polarization in the sample (see the Results section). Chemical homogeneity was tested on a lengthwise cut (nearly parallel to the [00.1] direction) through the whole crystal using an X-ray fluorescence (XRF) spectrometer with highly focused beam (Tornado M4, by Bruker Nano, Berlin, Germany). Distribution of niobium and tantalum was mapped over the entire sample with a spatial sampling distance of approximately $20 \mu \mathrm{m}$. The fluorescence maps were quantified using standard fundamental parameter analysis.

Figure $2 \mathrm{a}$ shows the distribution of tantalum (atom fraction $=[\mathrm{Ta}] /([\mathrm{Ta}]+[\mathrm{Nb}])$ ) over the whole measured sample area. Although integral compositional variation along the growth direction is small, there exist longitudinal structures with drastically reduced tantalum contents. These structures were the result of cellular growth owing to constitutional supercooling and occur mainly in regions of higher local growth velocity, i.e., the conical part with increasing crystal diameter and in regions with poor solute exchange in the melt, i.e., near the rotation axes. Figure $2 b$ shows the distribution over a (0001) sample cut perpendicular to the growth direction from the approximate axial position indicated by the arrow in Figure 2a. The mean $\mathrm{LiTaO}_{3}$ fraction measured over the full diameter of this sample was $48 \%$ with an RMS of $1.4 \%$. Figure 3 presents the distribution of LT fraction along the diameter of the sample, presented in Figure $2 \mathrm{~b}$. The measurement was performed along the vertical right edge.

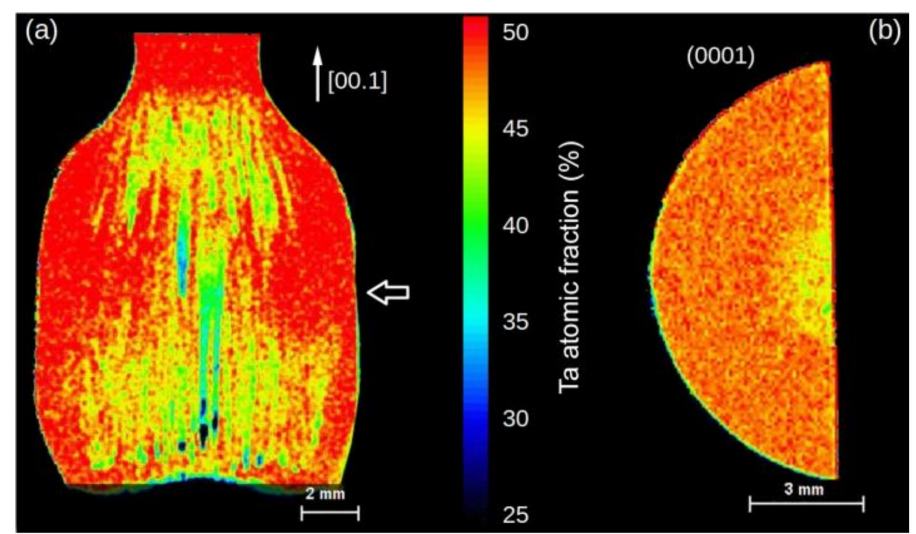

Figure 2. Element concentration mappings of a longitudinal (a) and transversal cut (b) through the LNT-50 crystal obtained by the XRF analysis. Axial position of the sample in (b) is indicated by the arrow in (a). 


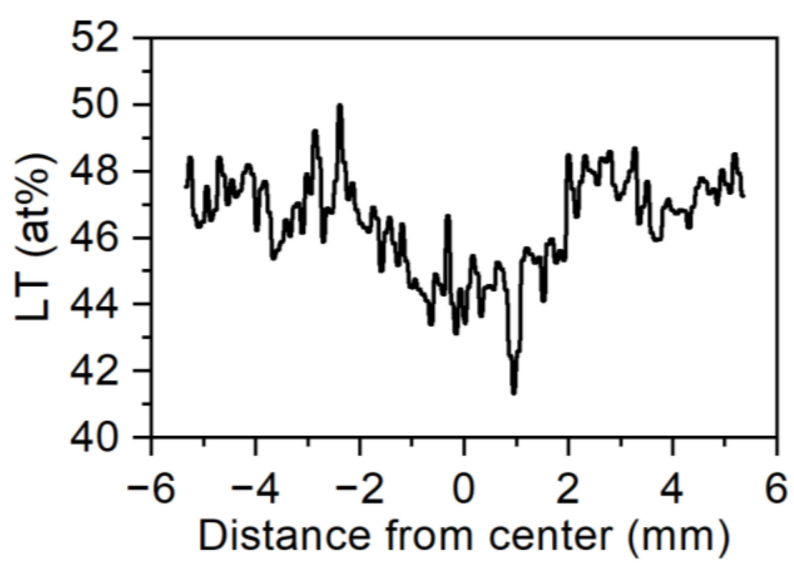

Figure 3. $\mathrm{LT}$ distribution in $\mathrm{LiNb}_{0.5} \mathrm{Ta}_{0.5} \mathrm{O}_{3}$ specimen along the full crystal diameter (right edge) of the sample in Figure $2 b$.

Additionally, nominally undoped $\mathrm{LiNbO}_{3}$ and $\mathrm{LiTaO}_{3}$ crystals of congruent composition, grown by the Czochralski technique at IMT were used in the current study for the electrical measurement.

\subsection{Specimens}

Two $\mathrm{LiNb}_{0.88} \mathrm{Ta}_{0.12} \mathrm{O}_{3}$ specimens, denoted as LNT88-01 and LNT88-02, were used in this study. They were prepared from a Y-cut plate with the approximate dimensions of $18 \times 18 \times 1 \mathrm{~mm}^{3}$ that was cut from the middle region of the related crystal boule, described above. Subsequently, the specimens were milled from the plate using a high-precision ultrasonic milling machine (UST-300, Dama Technologies, Häggenschwil, Switzerland) in the form of Y-cut plano-plano discs of $1 \mathrm{~mm}$ thickness and $8 \mathrm{~mm}$ diameter. Afterwards, they were polished (roughness $1 \mu \mathrm{m}$ ) and coated with keyhole-shaped $\mathrm{Pt} / \mathrm{Rh}$ electrodes with $300 \mathrm{~nm}$ thickness and $4 \mathrm{~mm}$ diameter by pulsed laser deposition (PLD). Further, the $\mathrm{LiNb}_{0.5} \mathrm{Ta}_{0.5} \mathrm{O}_{3}$ sample was prepared as Z-cut half-disc with $10 \mathrm{~mm}$ diameter and $0.5 \mathrm{~mm}$ thickness, cut from the middle part of the crystal boule, see the right part of Figure 2. This sample was designated as LNT50. Here, the electrodes were prepared by screen printing (print ink: Ferro Corporation, No. 6412 0410, Mayfield Heights, OH, USA) and subsequently annealed at $800{ }^{\circ} \mathrm{C}$ for about $30 \mathrm{~min}$. This short thermal treatment was expected not to cause a significant change of the sample properties. Such screen-printed Pt electrodes were excellent for the cases when robust temperature-stable electrodes were required. When annealed in the presence of oxygen platinum demonstrates high thermal and chemical stability, without any transition layers formed on its surface, which provides excellent electrical contact with other materials $[60,61]$. According to our experience, application of Pt screen-printed electrodes does not impact the high-temperature $Q$-factor of piezoelectric crystals of the langasite family, which show low losses even at elevated temperatures. Consequently, such electrodes are expected to have virtually no influence on the $Q$-factor of LNT at elevated temperatures where materials-related losses dominate.

Additionally Y-cut $\mathrm{LiNbO}_{3}$ and $\mathrm{LiTaO}_{3}$ plates of congruent composition with the dimensions of $10 \times 18 \times 2 \mathrm{~mm}^{3}$ and screen-printed electrodes were used in this work for conductivity studies with the aim to compare the electrical properties of LN, LNT and LT.

\subsection{Measurements and Analysis}

\subsubsection{Electrical Conductivity}

The studies of electrical conductivity as a function of temperature were performed by means of impedance spectroscopy using an impedance/gain-phase analyzer (Solartron 1260, Ametek Scientific Instruments, Hampshire, UK) in the frequency range from $1 \mathrm{~Hz}$ to $1 \mathrm{MHz}$ and in the temperature range from 400 to $700{ }^{\circ} \mathrm{C}$. The excitation voltage was $50 \mathrm{mV}$. The duration of sweep in in the frequency range that determines the data evaluation from 
$500 \mathrm{~Hz}$ to $1 \mathrm{MHz}$ was about $60 \mathrm{~s}$. The measurements were performed in air at atmospheric pressure while heating at a rate of $1 \mathrm{~K} / \mathrm{min}$. Below $400^{\circ} \mathrm{C}$ the impedance of the studied specimens was too high to acquire reliable data. For both types of the applied electrodes (PLD and screen-printed) we varied the excitation voltage up to $0.3 \mathrm{~V}$ for the comparison purposes. In all the cases the obtained results were the same.

The obtained impedance spectra were visualized in the complex plane, which involves plotting the imaginary part of the impedance against its real part (Nyquist plot). Subsequently, an electrical equivalent-circuit model consisting of a constant phase element (CPE) connected in parallel with a bulk resistance $R_{\mathrm{B}}$ was fitted to the measured data. The low frequency intercepts of $R_{\mathrm{B}}-\mathrm{CPE}$ semicircles in such a complex impedance plane were interpreted as bulk resistance and subsequently converted in the bulk conductivity, using the relation $\sigma=t\left(A \times R_{\mathrm{B}}\right)^{-1}$, where $t$ and $A$ are the thickness of the sample and the electrode area, respectively.

A Nyquist plot is exemplary given in Figure 4 for the studied specimens at $600{ }^{\circ} \mathrm{C}$. The representation of the resistivity is chosen to eliminate the geometrical factors of the samples (thickness and area). As seen from the figure, slightly depressed semicircles with almost similar resistance were obtained for LN and LT specimens. Such depression results from non-ideal capacitances and corresponds to exponents of the constant phase elements of 0.98 and 0.87 for $\mathrm{LiNbO}_{3}$ and $\mathrm{LiTaO}_{3}$ respectively. The corresponding exponents for LNT50 and LNT88-01 and LNT88-02 samples were equal to $0.98,0.99$ and 1.00 respectively. Further, as seen from Figure 4, the LNT88-01 and LNT88-02 specimens, which were manufactured from the same crystal boule are exhibiting different resistivity. This peculiarity will be discussed in the subsequent section.

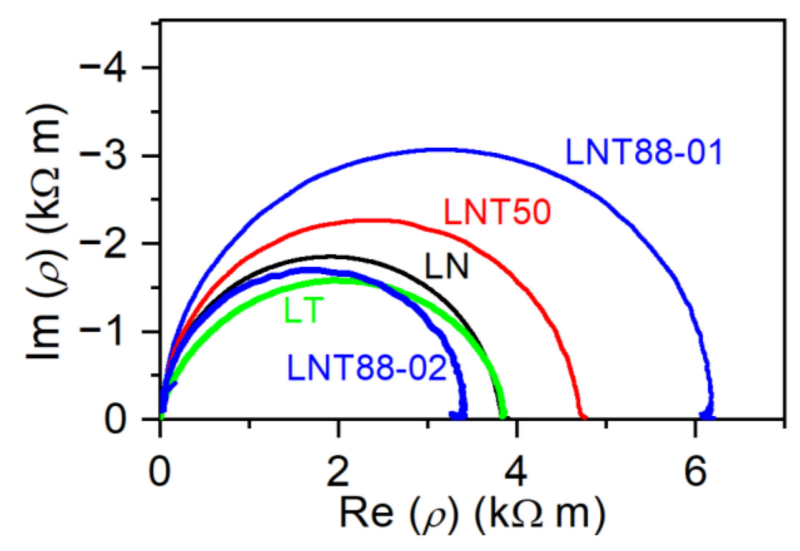

Figure 4. Complex resistivity of different $\mathrm{Li}(\mathrm{Nb}, \mathrm{Ta}) \mathrm{O}_{3}$ samples at $600{ }^{\circ} \mathrm{C}$, presented as the Nyquist plot.

\subsubsection{Acoustic Loss}

The investigations of acoustic losses were carried out by means of resonant piezoelectric spectroscopy (RPS) on LNT resonators, operated in the thickness-shear mode (TSM) and in the thickness mode (TM). Similarly to conductivity studies, these measurements were performed in air during heating with a rate of $1 \mathrm{~K}$ per min from $\mathrm{RT}$ to $700{ }^{\circ} \mathrm{C}$. The samples were electrically contacted using platinum foils on each side of the sample. With the objective to minimize damping from mechanical contact, only small areas near the edges of the samples were electrically contacted and mechanically clamped (Figure 5). The electrodes overlapped only in areas that were not mechanically clamped. 


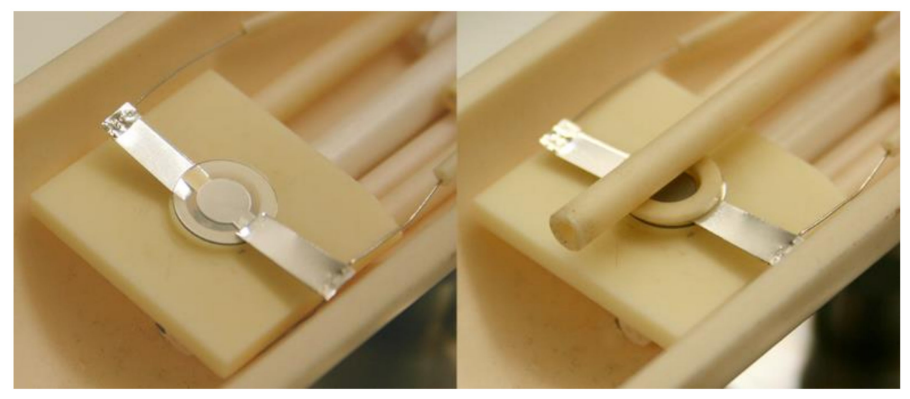

Figure 5. Arrangement of the studied sample for the high-temperature electrical and acoustic measurements. The pictures show the ring-type sample support without (left) and with (right) the upper $\mathrm{Al}_{2} \mathrm{O}_{3}$ ring and the rod that mechanically clamps the samples and the $\mathrm{Pt}$ foil together.

The real and imaginary parts of the impedance spectra were measured in the vicinity of the resonance frequency using a high-speed network analyzer (Agilent E5100A, HewlettPackard, Santa Clara, CA, USA). Subsequently, the impedance was transformed into admittance $Y=Z^{-1}$ and a Lorenz function was fitted to its real part (conductance $G$ ). This enabled determination of the resonance frequencies of the fundamental mode and of the subsequent harmonics and of the $Q$-factor for a given mode. Detailed description of data acquisition is given in [2]. Figure 6 exemplarily shows the real part of admittance, acquired for the LNT88-01 specimen at different temperatures. The frequency corresponds to the 1st harmonic of the TSM resonator. As seen from the figure, the resonance frequency (i.e., the conductance maximum) shifts with the temperature towards lower frequencies. Further, a broadening of the peak is observed at elevated temperatures. This implies an increase of the losses, which will be discussed in detail in Section 3. At $550{ }^{\circ} \mathrm{C}$ on the right shoulder of the conductance peak another small peak is observed at about $1.935 \mathrm{MHz}$, which is interpreted as a spurious mode and understood to originate from the "activity dips" phenomenon [60] (see discussion in Section 3).

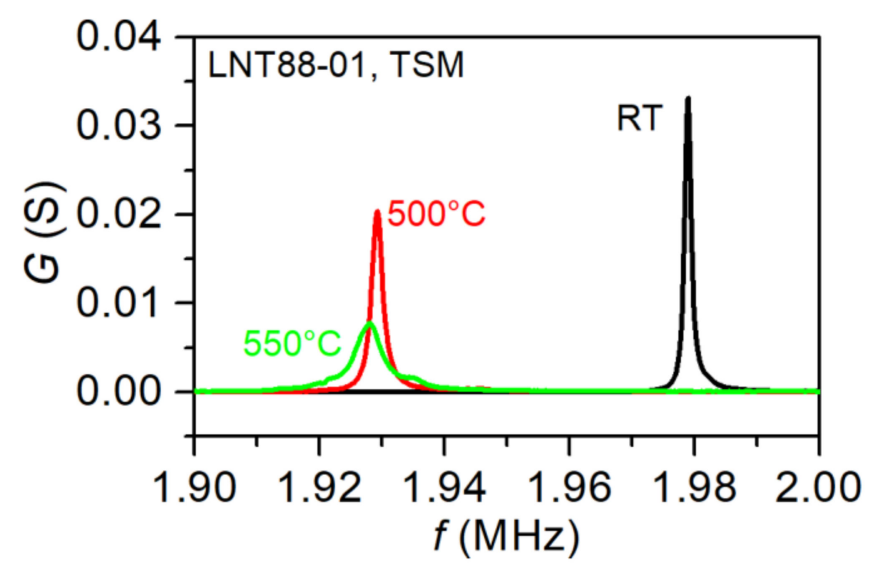

Figure 6. The real part of admittance as a function of frequency of LNT88-01 specimen, operated in the thickness-shear mode (TSM), acquired at different temperatures.

\section{Results}

\subsection{Electrical Conductivity}

The temperature dependent electrical conductivity of all studied specimens is shown in Figure 7 in the form of an Arrhenius plot. The measurements were performed in air in the temperature range from about 400 to $700{ }^{\circ} \mathrm{C}$. As seen from the figure, both materials exhibited similar electrical conductivities, reaching at $700{ }^{\circ} \mathrm{C}$ values of $1.52 \times 10^{-3} \mathrm{~S} / \mathrm{m}$ and $1.56 \times 10^{-3} \mathrm{~S} / \mathrm{m}$ for LN and LT, respectively. Further, the LNT88-01 and LNT8802 samples are showing different conductivity values in the whole measured temperature range. At $700{ }^{\circ} \mathrm{C}$ the $\sigma$ of LNT88-01 and LNT88-02 equaled $0.9 \times 10^{-3} \mathrm{~S} / \mathrm{m}$ and 
$1.9 \times 10^{-3} \mathrm{~S} / \mathrm{m}$, respectively. Such differences could not be solely attributed to the uncertainties in conductivity measurements (about $6 \%$ at $700{ }^{\circ} \mathrm{C}$ ). We assumed, that these divergences could be caused by the varying properties within a crystal boule such as an inhomogeneous distribution of $\mathrm{Nb}$ and Ta in grown LNT crystals (see also Table 1). We also note that the conductivity of both LN and LT is sensitive to even slight deviations in lithium stoichiometry $[16,23,41]$, which could also be the case of LNT specimens. The conductivity of sample LNT50 equaled $1.2 \times 10^{-3} \mathrm{~S} / \mathrm{m}$ at $700^{\circ} \mathrm{C}$. The value was 1.3 times lower than that of LN and about 1.3 higher than that of LNT88-01.

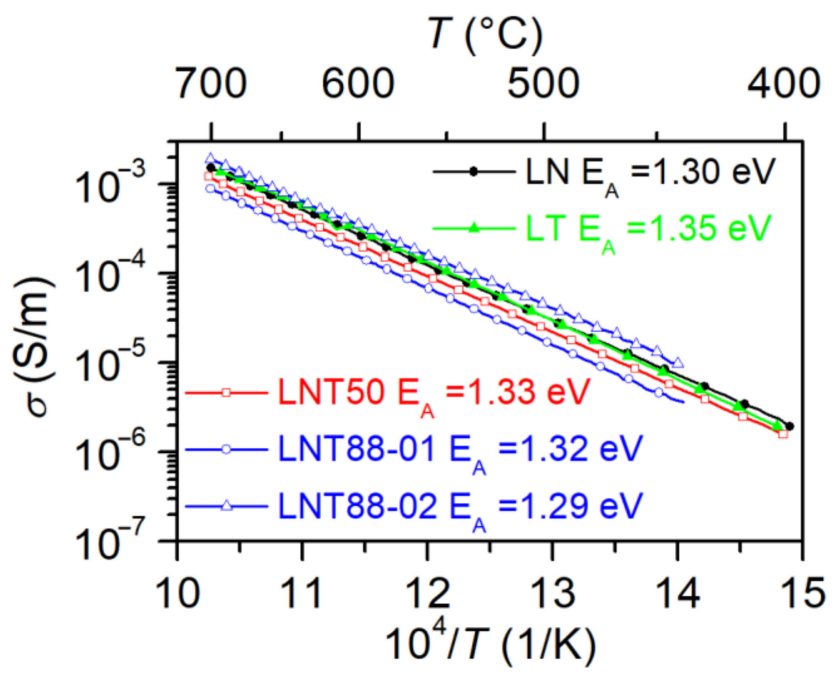

Figure 7. Conductivity of different $\mathrm{Li}(\mathrm{Nb}, \mathrm{Ta}) \mathrm{O}_{3}$ samples as a function of inverse temperature.

The conductivity of all the studied specimens increased linearly in the Arrhenius presentation (see Figure 7), indicating that it was governed by a single thermally activated process. Previously, the electrical conductivity of LT was investigated up to $800{ }^{\circ} \mathrm{C}$ in [23] and the authors assumed that the ionic conduction mechanism with lithium vacancies as a main charge carrier determines the conductivity at elevated temperatures as applied here. Similar conclusions were drawn in [24,26]. Further, the studies, performed in [16,29-32,41] show that the lithium ion migration via lithium vacancies was also the dominating transport mechanism in $\mathrm{LiNbO}_{3}$ at high temperatures. Therefore, it is plausible to assume that in LNT the conduction of Li-ions via Li-vacancies played a major role in the studied temperature range, similarly to both end components of $\mathrm{Li}(\mathrm{Nb}, \mathrm{Ta}) \mathrm{O}_{3}$-system. Considering that at $700{ }^{\circ} \mathrm{C}$ the conductivity is ionic, we claimed that it remains predominantly ionic down to $400{ }^{\circ} \mathrm{C}$ since we did not observe here a deviating slope with respect to $700^{\circ} \mathrm{C}$. Consequently, the conductivity $\sigma$ is written as [23]:

$$
\sigma=\frac{\sigma_{0}}{T} \exp \left(E_{A} / k T\right)
$$

where $\sigma_{0}, T, E_{A}$ and $k$ represent a pre-exponential constant, the absolute temperature, an activation energy and the Boltzmann constant, respectively. Following Equations (6) and (7), the relaxation time could be written as:

$$
\tau_{c}=\frac{\varepsilon_{i j} T}{\sigma_{0}} \exp \left(E_{A} / k T\right)
$$

Activation energies and pre-exponential factors, obtained by fitting of Equation (7) to the measured conductivity data are summarized in Table 2. Previously, close values of $\mathrm{E}_{\mathrm{A}}$ were obtained in $[16,30,31,41]$ for congruent $L N$ and in $[23,26]$ for congruent LT. 
Table 2. Parameters from fits of conductivity of $\mathrm{Li}(\mathrm{Nb}, \mathrm{Ta}) \mathrm{O}_{3}$ specimens.

\begin{tabular}{ccc}
\hline Sample & Activation Energy (eV) & $\begin{array}{c}\text { Pre-Exponential Factor } \\
\mathbf{( S K / m )}\end{array}$ \\
\hline LN & $1.30 \pm 0.06$ & $7.31 \times 10^{6}$ \\
LNT88-01 & $1.32 \pm 0.05$ & $6.72 \times 10^{6}$ \\
LNT88-02 & $1.29 \pm 0.04$ & $6.20 \times 10^{6}$ \\
LNT50 & $1.33 \pm 0.07$ & $7.07 \times 10^{6}$ \\
LT & $1.35 \pm 0.05$ & $1.49 \times 10^{7}$ \\
\hline
\end{tabular}

\subsection{Acoustic Loss}

The measured loss $Q^{-1}$ of the specimen LNT88-01 is shown in Figure 8 as a function of inverse temperature. The frequencies of the measurements correspond to the first, and fifth harmonics of the resonator that is operated in the TSM mode.

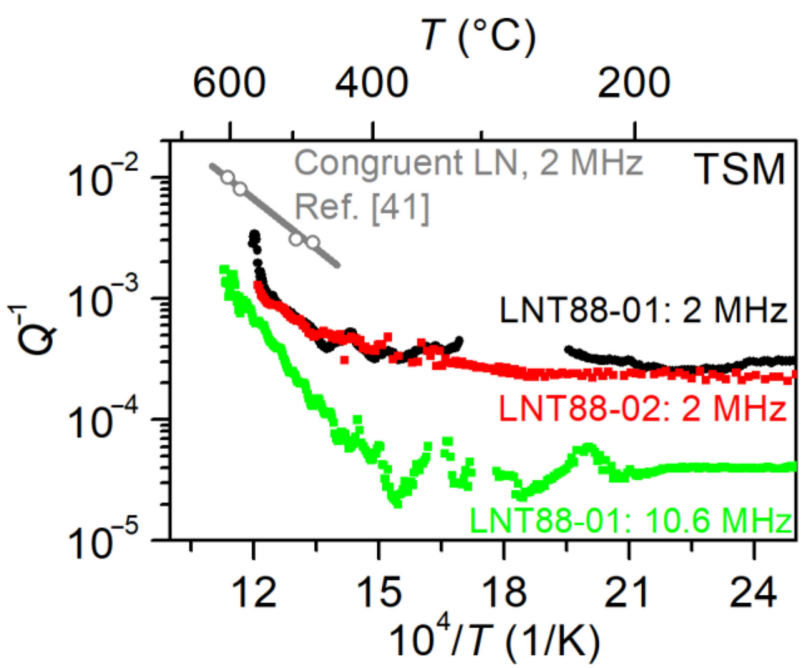

Figure 8. $Q^{-1}$ of LNT88 as a function of inverse temperature, compared to congruent LN, studied in [41].

A substantial number of sharp peaks were observed in the raw data for the first harmonic of LNT88-01 between 250 and $350^{\circ} \mathrm{C}$. These peaks are understood to originate from the "activity dips" phenomenon, caused by the coupling of the main mode with other spurious (parasitic) modes [62]. Such coupling does not allow for correct determination of the $Q$-factor. Therefore, the $Q^{-1}$ data in temperature ranges where activity dips occurred were removed from the results presented in Figure 8 to provide a more reliable and clear presentation of the measured data.

Further, the loss of higher harmonics was lower than that of the fundamental mode. This peculiarity could be attributed to the non-ideal diameter-to-thickness ratio of the studied resonator. As evaluated in [63] for resonators with a diameter-to-thickness ratio lower than 30, the non-material losses that arise from mounting increase with the frequency decrease must be considered. As it is widely known, the thickness-shear oscillations in any given partially electroded TSM resonator are confined to the area under and close to the electrodes. This phenomenon is known as energy trapping [64] and ensures high $Q$-factors. Strong energy trapping could be achieved by optimization of the electrode thickness and by choosing the optimal geometry of the resonator and of the electrodes $[64,65]$. Further, increasing the operational frequencies to higher harmonics could also increase the energy trapping, provided that the confinement of vibration energy is insufficient on the fundamental mode [64-66]. In our study, the geometry of LNT88 specimens was not ideal, which potentially explains relatively high losses at the fundamental mode. 
Additionally, the measured loss $Q^{-1}$ of the sample LNT88-02, determined for the first harmonic of a TSM resonator, is also shown in Figure 8 for validation of the results. As seen from the figure, the behavior of both resonators is nearly similar when operated in the fundamental mode. For LNT88-02 the losses between 250 and $350{ }^{\circ} \mathrm{C}$ could also be determined, as for this particular resonator no spurious modes were observed in this temperature range.

Figure 8 also compares the $Q^{-1}$ of LNT88 resonators to that of congruent LN specimen, studied previously in [41]. The LN resonator in [41] was prepared as X-cut, operated in TSM and the frequency corresponds to the fundamental mode. In the current study the LNT-88 resonators were prepared as Y-cut discs, however due to the crystal symmetry in both X-and Y-cuts the resonances could be excited in TSM and the material constants, which determine the resonance frequency and electromechanical coupling factor of TSM in X- and Y-cuts are equal $\left(C_{44}=C_{55} ; e_{15}=e_{24}\right.$ and $\left.\varepsilon_{11}=\varepsilon_{22}\right)[8,34,35,67]$. Remarkably, the losses in LNT88 resonators were substantially lower. We note however, that the results overlapped only partially, since the measurements of the LNT88 fundamental mode did not extend to the range of $\mathrm{LN}$ in [41].

As also seen from Figure $8, Q^{-1}$ remained nearly constant below about $450{ }^{\circ} \mathrm{C}$. Above that temperature, a rapid increase is observed for all measured frequencies. In the case of some other materials systems the high-temperature loss is attributed to the piezoelectric/carrier relaxation mechanism [50-52]. The same conclusion follows for LNT if the loss contribution is estimated using the materials constants for $\mathrm{LN}$, which is only doable this way due to missing data for LNT. Inserting materials constants for $600{ }^{\circ} \mathrm{C}\left(e_{15}=4.32 \mathrm{C} / \mathrm{m}^{2}\right.$; $\left.C_{44}=53.5 \mathrm{GPa} ; \varepsilon_{11}=6.02 \times 10^{-10} \mathrm{~F} / \mathrm{m}[34]\right)$, and the conductivity values (Table 2$)$ into Equation (5), the calculated contribution of piezoelectric/carrier relaxation matched the experimentally determined loss for the resonance frequencies of resonator LNT88-01, see Figure 9. The differences in absolute values of $Q^{-1}$ could be attributed to the material constants used for these calculations. Again, it has to be emphasized that we used $e_{15}, \varepsilon_{11}$ and $C_{44}$ for LN [34], while these values are different for LT and, obviously, also somewhat different for LNT.

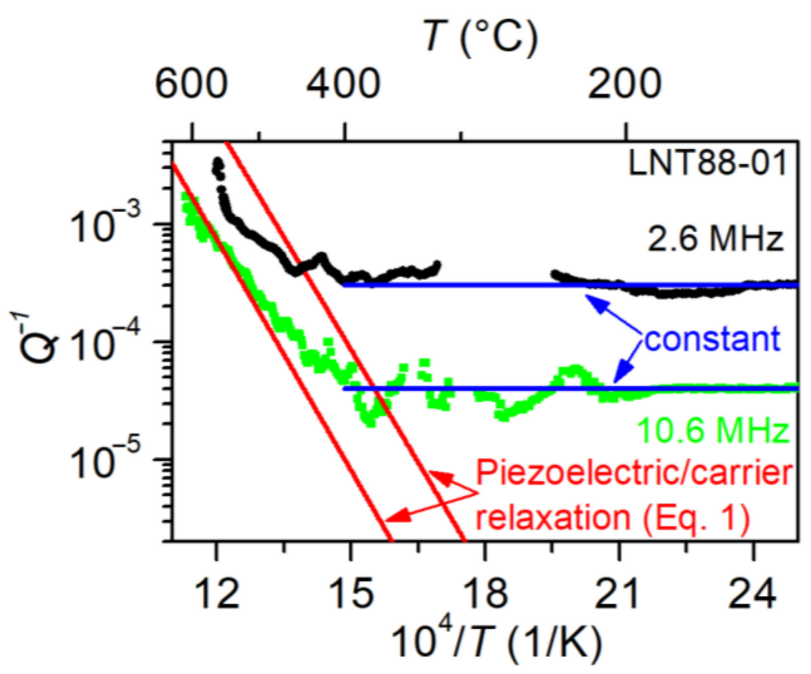

Figure 9. Calculated contribution of piezoelectric/carrier relaxation, compared to the measured $Q^{-1}$ of the LNT88-01 resonator.

Further, in order to minimize the influence of piezoelectric/carrier relaxation at a given anticipated application temperature, the operating frequencies of LNT resonators can be chosen accordingly. For example, a $2 \mathrm{MHz}$ resonator could be operated up to about $450{ }^{\circ} \mathrm{C}$ without significant loss increase (Figure 9). Equation (5) enables one to estimate favorable frequencies for the high-temperature applications of LNT TSM resonators. Figure 10 shows the resulting piezoelectric/carrier relaxation losses for different operating frequencies. 
As seen from Figure 10, a decrease of the operating frequency to $100 \mathrm{kHz}$ prevented the application of such resonators between about 450 and $1000^{\circ} \mathrm{C}$ but enabled its use above that temperature provided that the material was thermally stable. Increase of the frequency to $30 \mathrm{MHz}$ allowed application temperature up to about $750^{\circ} \mathrm{C}$. For both cases it was assumed that $Q^{-1}=2 \times 10^{-3}$ was the maximum $Q^{-1}$, required for accurate frequency determination.

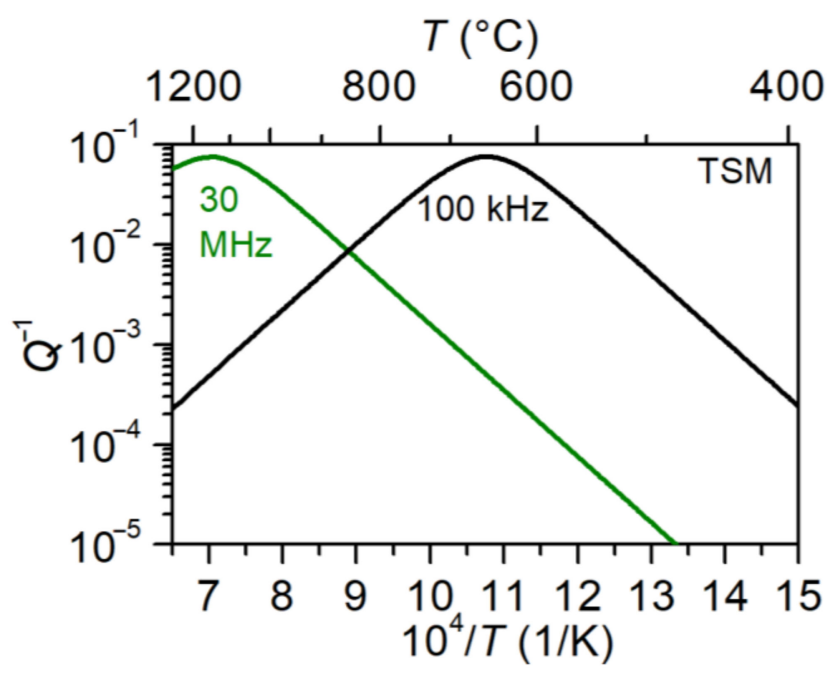

Figure 10. Estimated contribution of the piezoelectric/carrier relaxation to the overall loss of LN TSM resonators, calculated for different operation frequencies.

Figure 11 presents the measured loss $Q^{-1}$ of LNT50 specimen as a function of inverse temperature, compared to that of congruent LN presented in [16]. Both samples are operated in TM. Further, resonator LNT50 is operated at its third harmonic. Reliable measurements for sample LNT50 were obtained only above $400{ }^{\circ} \mathrm{C}$. Below that temperature a substantial number of spurious modes in the vicinity of the resonant mode was observed in the spectra and did not allow for determination of the $Q$-factor.

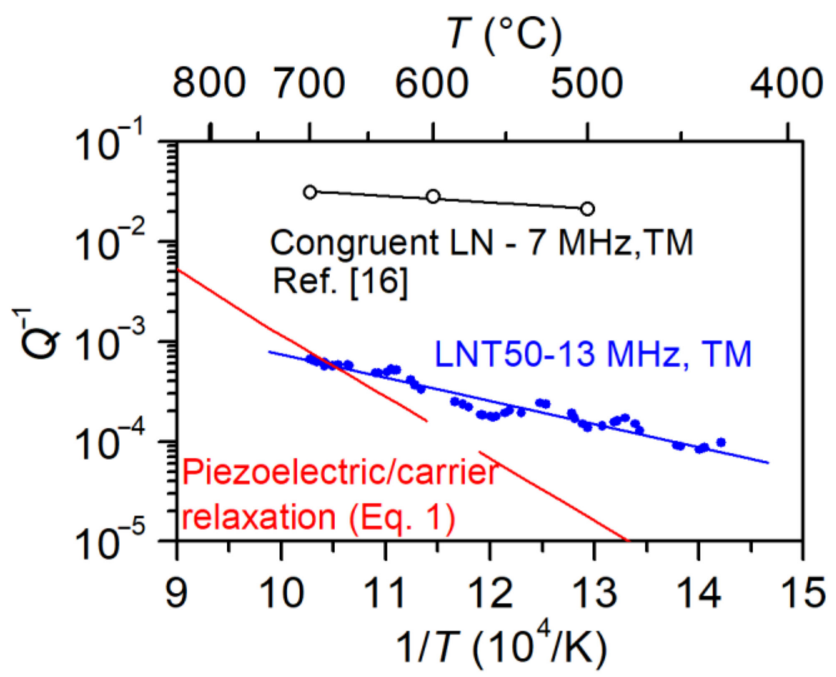

Figure 11. Measured $Q^{-1}$ of LNT50 compared to that of LN, determined in [16].

Similarly to TSM LNT resonators, the piezoelectric/carrier contribution to $Q^{-1}$ could be calculated for LNT50 using Equation (5) and the data, obtained from conductivity measurements (Table 2). For the same reasons as for samples LNT88, these calculations are done using the material constants for $\mathrm{LiNbO}_{3}\left(e_{33}=1.72 \mathrm{C} / \mathrm{m}^{2} ; C_{33}=227.9 \mathrm{GPa}\right.$; $\left.\varepsilon_{33}=4.32 \times 10^{-10} \mathrm{~F} / \mathrm{m}[35,67]\right)$. The result of the calculation is plotted in Figure 11. As 
seen from figure, the piezoelectric/carrier relaxation might significantly contribute to the overall loss of the $13 \mathrm{MHz} \mathrm{TM}$ resonator above about $700{ }^{\circ} \mathrm{C}$, only. Therefore, the exponential increase of $Q^{-1}$ in the range $400-700{ }^{\circ} \mathrm{C}$ has presumably a different nature. One possible explanation of this increase is the undefined domain structure of the LNT50. As briefly mentioned in Section 2.1, the crystal was not poled intentionally. The existence of resonances during electrical excitation shows however, that the sample has sufficiently large areas with identical orientation of the polarization. On the other side, some regions of the sample could have a different polarization, which would influence the overall losses. As a consequence, the loss determined here represents the upper limit and would reach lower values for a single-domain structure if not yet present. This issue must be studied in more detail and will be a subject of subsequent investigations.

As seen from Figure 11, the overall loss of LNT50 was substantially lower, comparing to congruent $\mathrm{LN}$ in the entire measured temperature range, which enabled improved accuracy in frequency determination of such resonators. It is however worth noting that the operating frequency of the LN resonator, studied in [16] is lower, therefore the maximum of piezoelectric/carrier relaxation contribution is shifted towards lower temperatures in this specimen. This shift could be calculated with the help of Equation (5) and equals only about $50 \mathrm{~K}$, comparing to the LNT50. In other words, the difference of overall $Q^{-1}$ in LN and LNT50 could not be attributed to the different operation frequencies and is rather explained by the intrinsic properties of both materials.

It should be emphasized that the loss occurring at high temperatures is determined by intrinsic materials properties and, therefore, reflected in a correct manner. At lower temperatures, however, the shape and size of the samples impacts the resonator quality factor. In this respect, the dimensions sample LNT50 was not optimal, which primarily results from the relatively small crystal boules of grown LNT (see Section 3). Preparing the specimen with favorable geometry and diameter-to-thickness ratio should result in improved piezoelectric response and, consequently, lower $Q^{-1}$ in the lower part of the measured temperature range. This issue will be the subject of subsequent studies if larger samples are available. Further work is intended to uncover the interplay between microscopic and macroscopic features by regarding a larger temperature range and by extending studies about charge carrier/defect relaxation as given, e.g., in [68] within the framework of collaborative research.

\section{Conclusions}

In summary, the electrical and electromechanical properties of lithium niobate-tantalate solid solutions with different $\mathrm{Nb} / \mathrm{Ta}$ ratios were studied at elevated temperatures and compared to those of $\mathrm{LiNbO}_{3}$ and $\mathrm{LiTaO}_{3}$. The measured temperature dependence of electrical conductivity in air up to $700{ }^{\circ} \mathrm{C}$ shows similar behavior for all studied samples. Consequently, the dominating transport mechanism in LNT in the range $400-700{ }^{\circ} \mathrm{C}$ was attributed to the lithium ion migration via lithium vacancies as found in LN.

Further, the study of the acoustic loss in LNT resonators, operated in the thicknessshear mode, revealed rapid, frequency dependent loss increase at elevated temperatures. This loss increase was correlated with conductivity measurements and attributed to the piezoelectric/carrier relaxation mechanism. Further, it is shown that minimization of the influence of conductivity-related losses at a given anticipated application temperature could be achieved by an appropriate choice of operating frequencies.

Finally, the study revealed that the temperature-dependent loss in LNT specimens was generally lower than that of congruent LN for both thickness and thickness-shear mode resonators. The domain structure of the LNT50 specimen, operated in the thickness mode, was unknown. However, clear resonances were observed, which indicates largely uniform polarization of the domains or even a single domain. Since different orientations of polarization cannot be excluded, the loss was potentially affected. As a consequence, the $Q^{-1}$ presented here for the LNT50 specimen is the upper limit and would reach lower for a single-domain structure if not yet present. 
Author Contributions: Conceptualization, Y.S. and H.F.; Crystal growth and structural analysis D.R., B.R. and S.G.; Sample preparation, S.G., B.J. and Y.S.; Electrical and acoustic measurements, B.J., A.K. and Y.S.; Writing—original draft preparation, Y.S.; Writing—review and editing, H.F. All authors have read and agreed to the published version of the manuscript.

Funding: Research grants from the Deutsche Forschungsgemeinschaft (DFG, German Research Foundation, FR1301/32-1, SU1261/1-1, GA2403/7-1, FR1301/42-1) and Russian Foundation for Basic Research (grant 19-52-12044) supported this work.

Institutional Review Board Statement: Not applicable.

Informed Consent Statement: Not applicable.

Data Availability Statement: All relevant data presented in the article are stored according to institutional requirements and as such are not available online. However, all data used in this manuscript can be made available upon request to the authors.

Acknowledgments: The authors from Clausthal University of Technology acknowledge the support of the Energie-Forschungszentrum Niedersachsen, Goslar, Germany. M. Brützam und M. Stypa from Leibniz-Institut für Kristallzüchtung, Berlin, Germany are thankfully acknowledged for their technical assistance in crystal growth. The authors are indebted to S. Lenk (Clausthal University of Technology) for the elemental analysis by EDX. We acknowledge the support by Open Access Publishing Fund of Clausthal University of Technology.

Conflicts of Interest: The authors declare no conflict of interest.

\section{References}

1. Tuloup, C.; Harizi, W.; Aboura, Z.; Meyer, Y.; Khellil, K.; Lachat, R. On the use of in-situ piezoelectric sensors for the manufacturing and structural health monitoring of polymer-matrix composites: A literature review. Compos. Struct. 2019, 215, 127-149. [CrossRef]

2. Fritze, H. High-temperature bulk acoustic wave sensors. Meas. Sci. Technol. 2011, 22, 12002. [CrossRef]

3. Stevenson, T.; Martin, D.G.; Cowin, P.I.; Blumfield, A.; Bell, A.J.; Comyn, T.P.; Weaver, P.M. Piezoelectric materials for high temperature transducers and actuators. J. Mater. Sci. Mater. Electron. 2015, 26, 9256-9267. [CrossRef]

4. Khesro, A.; Wang, D.; Hussain, F.; Sinclair, D.C.; Feteira, A.; Reaney, I.M. Temperature stable and fatigue resistant lead-free ceramics for actuators. Appl. Phys. Lett. 2016, 109, 142907. [CrossRef]

5. Zhang, S.; Xia, R.; Lebrun, L.; Anderson, D.; Shrout, T.R. Piezoelectric materials for high power, high temperature applications. Mater. Lett. 2005, 59, 3471-3475. [CrossRef]

6. Ohsato, H.; Iwataki, T.; Morikoshi, H. Crystal structure and piezoelectric properties of four component langasite $\mathrm{A}_{3} \mathrm{BGa}_{3} \mathrm{Si}_{2} \mathrm{O}_{14}$ $(\mathrm{A}=\mathrm{Ca}$ or $\mathrm{Sr}, \mathrm{B}=\mathrm{Ta}$ or $\mathrm{Nb})$. Trans. Electr. Electron. Mater. 2012, 13, 171-176. [CrossRef]

7. Suhak, Y.; Schulz, M.; Sotnikov, A.; Schmidt, H.; Ganschow, S.; Sakharov, S.; Fritze, H. Dielectric, piezoelectric and elastic constants of $\mathrm{Ca}_{3} \mathrm{TaGa}_{3} \mathrm{Si}_{2} \mathrm{O}_{14}$ single crystals at elevated temperatures. Integr. Ferroelectr. 2018, 537, 255-263. [CrossRef]

8. Volk, T.; Wöhlecke, M. Lithium Niobate: Defects, Photorefraction and Ferroelectric Switching; Springer: Berlin/Heidelberg, Germany, 2008.

9. Sugak, D.; Zhydachevskii, Y.; Suhak, Y.; Buryy, O.; Ubizskii, S.; Solskii, I.; Schrader, M.; Becker, K.D. In-situ investigation of optical absorption changes in $\mathrm{LiNbO}_{3}$ during reducing/oxidizing high temperature treatments. J. Phys. Cond. Matter 2007, $19,086211$. [CrossRef]

10. Solskii, I.M.; Sugak, D.Y.; Vakiv, M.M. Growing large size complex oxide single crystals by Czochralski technique for electronic devices. Acta Physica. Polonica A 2013, 124, 314-320. [CrossRef]

11. Bordui, P.F.; Notwood, R.G.; Bird, C.D.; Carella, J.T. Stoichiometry issues in single-crystal lithium tantalate. J. Appl. Phys. 1995, 78, 4647-4650. [CrossRef]

12. Kawamata, A.; Hosaka, H.; Morita, T. Non-hysteresis and perfect linear piezoelectric performance of a multilayered lithium niobate actuator. Sens. Actuators A 2007, 135, 782-786. [CrossRef]

13. Nakamura, K.; Shimizu, H. Hysteresis-free piezoelectric actuators using $\mathrm{LiNbO}_{3}$ plates with a ferroelectric inversion layer. Ferroelectrics 1989, 93, 211-216. [CrossRef]

14. Samuelsen, E.J.; Grande, A.P. The ferroelectric phase transition in $\mathrm{LiTaO}_{3}$ studied by neutron scattering. Z. Physik B 1976, 24, 207-210. [CrossRef]

15. Damjanovic, D. Materials for high-temperature piezoelectric transducers. Curr. Opin. Solid St. M. 1998, 3, 469-473. [CrossRef]

16. Weidenfelder, A.; Shi, J.; Fielitz, P.; Borchardt, G.; Becker, K.D.; Fritze, H. Electrical and electromechanical properties of stoichiometric lithium niobate at high temperatures. Solid State Ion. 2012, 225, 26-29. [CrossRef]

17. Schirmer, O.F.; Thiemann, O.; Wöhlecke, M. Defects in $\mathrm{LiNbO}_{3}$-1. Experimental Aspects. J. Phys. Chem. Solids 1991, 52, 185-200. [CrossRef]

18. Donnerberg, H.; Tomlinson, S.M.; Catlow, C.R.A.; Schirmer, O.F. Computer-simulation studies of intrinsic defects in $\mathrm{LiNbO}_{3}$ crystals. Phys. Rev. B 1989, 40, 11909-11916. [CrossRef] 
19. Abrahams, S.C.; Marsh, P. Defect Structure Dependence on Composition in Lithium Niobate. Acta Crystallogr. B 1986, $42,61-68$. [CrossRef]

20. Furukawa, Y.; Kitamura, K.; Suzuki, E.; Niwa, K. Stoichiometric $\mathrm{LiTaO}_{3}$ single crystal growth by double crucible Czochralski method using automatic powder supply system. J. Cryst. Growth 1999, 197, 889-895. [CrossRef]

21. Kitamura, K.; Furukawa, Y.; Niwa, K.; Goplan, V.; Mitchell, T.E. Crystal growth and low coercive field $180^{\circ}$ domain switching characteristics of stoichiometric $\mathrm{LiTaO}_{3}$. Appl. Phys. Lett. 1998, 73, 3073-3076. [CrossRef]

22. Krampf, A.; Imlau, M.; Suhak, Y.; Fritze, H.; Sanna, S. Evaluation of similarities and differences of $\mathrm{LiTaO}_{3}$ and $\mathrm{LiNbO}_{3}$ based on high-T-conductivity, nonlinear optical fs-spectroscopy and ab initio modeling of polaronic structures. New J. Phys. 2021, in press. [CrossRef]

23. Huanosta, A.; West, A.R. The electrical properties of ferroelectric $\mathrm{LiTaO}_{3}$ and its solid solutions. J. Appl. Phys. 1987, 61, 5386-5391. [CrossRef]

24. Sinclair, D.C.; West, A.R. Electrical properties of a $\mathrm{LiTaO}_{3}$ single crystal. Phys. Rev. B 1989, 39, 13486-13492. [CrossRef]

25. Ming, D.; Reau, J.M.; Ravez, J.; Gitae, J.; Hagenmuller, P. Impedance-spectroscopy analysis of a $\mathrm{LiTaO}_{3}$-type single crystal. J. Solid State Chem. 1995, 116, 185-192. [CrossRef]

26. Palatnikov, M.N.; Sandler, V.A.; Yatsenko, A.V.; Sidorov, N.V.; Evdokimov, S.V.; Makarova, O.V. Anisotropic electrical conductivity and dielectric properties of $\mathrm{LiTaO}_{3}$ crystals in the temperature range 290-900 K. Inorg. Mater. 2015, 51, 685-695. [CrossRef]

27. Smyth, D.M. Defects and transport in $\mathrm{LiNbO}_{3}$. Ferroelectrics 1983, 50, 93-102. [CrossRef]

28. Lanfredi, S.; Rodrigues, A.C.M. Impedance spectroscopy study of the electrical conductivity and dielectric constant of polycrystalline $\mathrm{LiNbO}_{3}$. J. Appl. Phys. 1999, 86, 2215-2219. [CrossRef]

29. Chen, R.H.; Chen, L.; Chia, C. Impedance spectroscopic studies on congruent $\mathrm{LiNbO}_{3}$ single crystal. J. Phys. Condens. Matter 2007, 19, 086225. [CrossRef]

30. Ruprecht, B.; Rahn, J.; Schmidt, H.; Heitjans, P. Low-Temperature DC Conductivity of $\mathrm{LiNbO}_{3}$ Single Crystals. Z. Phys. Chem. 2012, 226, 431-437. [CrossRef]

31. El-Bachiri, A.; Bennani, F.; Bousselamti, M. Ionic and polaronic conductivity of lithium niobate. Spectrosc. Lett. 2014, 47, 374-380. [CrossRef]

32. Efremov, V.V.; Shcherbina, O.B.; Palatnikov, M.N.; Masloboeva, S.M. Comparative investigation of electrophysical characteristics of ceramic and single crystal $\mathrm{LiNbO}_{3}$. J. Phys. Conf. Ser. 2020, 1658, 012010. [CrossRef]

33. Yamada, T.; Iwasaki, H.; Niizeki, N. Piezoelectric and elastic properties of $\mathrm{LiTaO}_{3}$ : Temperature characteristics. Jpn. J. Appl. Phys. 1969, 8, 1127-1132. [CrossRef]

34. De Castilla, H.; Belanger, P.; Zednik, R.J. High temperature characterization of piezoelectric lithium niobate using electrochemical impedance spectroscopy resonance method. J. Appl. Phys. 2017, 122, 244103. [CrossRef]

35. Chen, F.; Kong, L.; Song, W.; Jiang, C.; Tian, S.; Yu, F.; Qin, L.; Wang, C.; Zhao, X. The electromechanical features of LiNbO 3 crystal for potential high temperature piezoelectric applications. J. Mater. 2019, 5, 73-80. [CrossRef]

36. Rüsing, M.; Sanna, S.; Neufeld, S.; Berth, G.; Schmidt, W.G.; Zrenner, A.; Yu, H.; Wang, Y.; Zhang, H. Vibrational properties of $\mathrm{LiNb}_{1-\mathrm{x}} \mathrm{Ta}_{\mathrm{x}} \mathrm{O}_{3}$ mixed crystals. Phys. Rev. B 2016, 93, 184305. [CrossRef]

37. Riefer, A.; Sanna, S.; Schmidt, W.G. LiNb $\mathrm{Li}_{1-\mathrm{x}} \mathrm{Ta}_{\mathrm{x}} \mathrm{O}_{3}$ electronic structure and optical response from first principles. Ferroelectrics 2013, 447, 78. [CrossRef]

38. Huband, S.; Keeble, D.S.; Zhang, N.; Glazer, A.M.; Bartasyte, A.; Thomas, P.A. Crystallographic and optical study of LiNb $1-x \mathrm{Ta}_{\mathbf{x}} \mathrm{O}_{3}$. Acta Cryst. B 2017, 73, 498. [CrossRef]

39. Glazer, A.M.; Zhang, N.; Bartasyte, A.; Keeble, D.S.; Huband, S.; Thomas, P.A. Observation of unusual temperature-dependent stripes in $\mathrm{LiTaO}_{3}$ and $\mathrm{LiNb}_{1-\mathrm{x}} \mathrm{Ta}_{x} \mathrm{O}_{3}$ crystals with near-zero birefringence. J. Appl. Cryst. 2010, 43, 1305. [CrossRef]

40. Palatnikov, M.N.; Sandler, V.A.; Sidorov, N.V.; Makarova, O.V.; Manukovskaya, D.V. Conditions of application of LiNbO 3 based piezoelectric resonators at high temperatures. Phys. Lett. A 2020, 384, 126289. [CrossRef]

41. Weidenfelder, A.; Schulz, M.; Fielitz, P.; Shi, J.; Borchardt, G.; Becker, K.D.; Fritze, H. Electronic and ionic transport mechanisms of stoichiometric lithium niobate at high temperatures. MRS Proc. 2013, 1519, 1-7. [CrossRef]

42. Parks, D.A.; Zhang, S.; Tittmann, B.R. High-Temperature $\left(>500^{\circ} \mathrm{C}\right)$ Ultrasonic transducers: An experimental comparison among three candidate piezoelectric materials. IEEE Trans. Ultrason. 2013, 60, 1010-1015. [CrossRef]

43. Hauser, R.; Reindl, L.; Biniasch, J. High-temperature stability of $\mathrm{LiNbO}_{3}$-based SAW devices. IEEE Ultrason. Symp. 2003, 1, 192-195.

44. Garavito, R.; Villafuerte-Castrejón, M.E.; Valenzuela, R.; West, A.R. Phase equilibria in the system $\mathrm{Li}_{2} \mathrm{O}_{-} \mathrm{Nb}_{2} \mathrm{O}_{5}-\mathrm{Ta}_{2} \mathrm{O}_{5} \cdot \mathrm{Br}$. Ceram . Trans. J. 1985, 84, 104-108.

45. Fernandez-Ruiz, R.; Bermudez, V. Determination of the Ta and $\mathrm{Nb}$ ratio in $\mathrm{LiNb}_{1-\mathrm{x}} \mathrm{Ta}_{\mathrm{x}} \mathrm{O}_{3}$ by total reflection $\mathrm{X}$-ray fluorescence spectrometry. Spectrochim. Acta B 2005, 60, 231. [CrossRef]

46. Wood, I.G.; Daniel, P.; Brown, R.H.; Glazer, A.M. Optical birefringence study of the ferroelectric phase transition in lithium niobate tantalate mixed crystals: $\mathrm{LiNb}_{1-\mathrm{x}} \mathrm{Ta}_{\mathrm{x}} \mathrm{O}_{3}$. J. Phys. Cond. Matter 2008, 20, 235237. [CrossRef]

47. Bartasyte, A.; Glazer, A.M.; Wondre, F.; Prabhakaran, D.; Thomas, P.A.; Huband, S.; Keeble, D.S.; Margueron, S. Growth of $\mathrm{LiNb}_{1-\mathrm{x}} \mathrm{Ta}_{\mathrm{x}} \mathrm{O}_{3}$ solid solution crystals. Mater. Chem. Phys. 2012, 134, 728. [CrossRef]

48. Bak, K.Y.; Tan, K.B.; Khaw, C.C.; Zainal, Z.; Tan, P.Y.; Chon, M.P. Structural and electrical properties of Nb-substituted $\mathrm{LiTa}_{1-\mathrm{x}} \mathrm{Nb}_{\mathrm{x}} \mathrm{O}_{3}$. Sains. Malays. 2014, 43, 1573-1582. 
49. Xue, D.; Betzler, K.; Hesse, H. Dielectric properties of lithium niobate-tantalate crystals. Solid State Commun. 2000, 115, 581-585. [CrossRef]

50. Johnson, W.L.; Kim, S.A.; Uda, S.; Rivenbark, C.F. Contributions to anelasticity in langasite and langatate. J. Appl. Phys. 2011, 110, 123528. [CrossRef]

51. Hirschle, C.; Schreuer, J. High-temperature ultrasound attenuation in langasite and langatate. IEEE Trans. Ultrason. Ferroelect. Freq. Control 2018, 65, 1250-1257. [CrossRef] [PubMed]

52. Suhak, Y.; Schulz, M.; Johnson, W.L.; Sotnikov, A.; Schmidt, H.; Fritze, H. Electromechanical properties and charge transport of $\mathrm{Ca}_{3} \mathrm{TaGa}_{3} \mathrm{Si}_{2} \mathrm{O}_{14}$ (CTGS) single crystals at elevated temperatures. Solid State Ion. 2018, 317, 221-228. [CrossRef]

53. Mason, W.P. Physical Acoustics, Principles and Methods; Academic Press: New York, NY, USA, 1965; Volume 3B.

54. Tabrizian, R.; Rais-Zadeh, M.; Ayazi, F. Effect of Phonon Interactions on Limiting the fQ Product of Micromechanical Resonators. IEEE Transducers 2009, 2131-2134. [CrossRef]

55. Nowick, A.S.; Berry, B.S. Anelastic Relaxation in Crystalline Solid; Academic Press: New York, NY, USA, 1972.

56. Hutson, A.R.; White, D.L. Elastic wave propagation in piezoelectric semiconductors. J. Appl. Phys. 1962, 33, 40-47. [CrossRef]

57. Ikeda, T. Fundamentals of Piezoelectricity; Oxford University Press: Oxford, UK, 1990.

58. Roshchupkin, D.; Emelin, E.; Plotitcyna, O.; Rashid, F.; Irzhak, D.; Karandashev, V.; Orlova, T.; Targonskaya, N.; Sakharov, S.; Mololkin, A.; et al. Single crystals of ferroelectric lithium niobate-tantalate $\mathrm{LiNb}_{1-\mathrm{x}} \mathrm{Ta}_{\mathrm{x}} \mathrm{O}_{3}$ solid solutions for high-temperature sensor and actuator applications. Acta Cryst. B 2020, 76, 1071-1076. [CrossRef]

59. Reiche, P.; Hermoneit, B.; Schultze, D. A modified heater system for rf-Czochralski equipments. Cryst. Res. Technol. 1985, 20, 845-849. [CrossRef]

60. Vechembre, J.B.; Fox, G.R. Sintering of screen-printed platinum thick films for electrode applications. J. Mater. Res. 2001, 16, 922-931. [CrossRef]

61. Golosov, D.A.; Okojie, J.E.; Zavadski, S.M.; Rudenkov, A.S.; Melnikov, S.N.; Kolos, V.V. Stability of the platinum electrode during high temperature annealing. Thin Solid Films 2018, 661, 53-59. [CrossRef]

62. Ballato, A. Electronic Activity Dip Measurement. IEEE Trans. Instr. Meas. 1978, 27, 59-65. [CrossRef]

63. Ballato, A.; Gualtieri, J.G. Advances in high-Q piezoelectric resonator materials and devices. IEEE Trans. Ultrason. Ferroelect. Freq. Control 1994, 41, 834-844. [CrossRef]

64. Shockley, W.; Curran, D.R.; Koneval, D.J. Trapped energy modes in quartz filter crystals. J. Acoust. Soc. Am. 1967, $41,981$. [CrossRef]

65. Wang, J.; Shen, L.; Yang, J. Effects of electrodes with continuously varying thickness on energy trapping in thickness-shear mode quartz resonators. Ultrasonics 2008, 48, 150-154. [CrossRef] [PubMed]

66. Cassiede, M.; Paillol, J.H.; Pauly, J.; Daridon, J.-L. Electrical behaviour of AT-cut quartz crystal resonators as a function of overtone number. Sens. Actuators A 2010, 159, 174-183. [CrossRef]

67. Ledbetter, H.; Ogi, H.; Nakamura, N. Elastic, anelastic, piezoelectric coefficients of monocrystal lithium niobate. Mech. Mater. 2004, 36, 941-947. [CrossRef]

68. Vittadello, L.; Bazzan, M.; Messerschmidt, S.; Imlau, M. Small polaron hopping in Fe:LiNbO $\mathrm{L}_{3}$ as a function of temperature and composition. Crystals 2019, 8, 294. [CrossRef] 